\title{
Cavity Preparation by Laser in Primary Teeth: Effect of 2 Levels of Energy Output on the Shear Bond Strength of Composite Restoration to Dentin
}

\author{
Mehrsa Paryab $^{1^{*}}$, Shahrzad Sharifi ${ }^{1}$, Mohammad Javad Kharazifard ${ }^{2}$, Nazanin Kumarci ${ }^{3}$ \\ 'Department of Paediatric Dentistry, International Campus, Tehran University of Medical Sciences, Tehran, Iran \\ ${ }^{2}$ School of Dentistry, Tehran University of Medical Sciences, Tehran, Iran \\ ${ }^{3}$ Department of Restorative Dentistry, International Campus, Tehran University of Medical Sciences, Tehran, Iran
}

\author{
*Correspondence to \\ Mehrsa Paryab, DDS, MS; \\ Department of Pediatric Dentistry, \\ Faculty of Dentistry, Mahan St, \\ Zam-Zam St, Navabe Safavi Ave, \\ Tehran, Iran. \\ Tel: +989121091675 \\ Fax: +982155851141 \\ Email: drmparyab@yahoo.com
}

Published online July 6, 2018

\begin{abstract}
Introduction: One of the main applications of laser in dentistry is the removal of dental caries and preparation of restorative cavities. The morphology and wettability of laser prepared surfaces are different from that of those prepared with conventional method which may affect the quality of the adhesive potential of bonding agents in these surfaces. This study aimed to assess the shear bond strength of a total-etch and self-etch adhesive system to primary tooth dentin prepared by two different energy densities of Er:YAG laser in comparison with surfaces prepared by bur.

Methods: A total of 60 human primary second molars extracted for orthodontic purposes were selected and randomly divided into 3 main groups of equal $(n=20)$. Group A: Preparation of dentin surface by bur; group B: Preparation of dentin surface by laser with $300 \mathrm{~mJ}$ energy level; group C: Preparation of dentin surface by laser with $400 \mathrm{~mJ}$ energy level. In each of the main groups, the teeth were randomly assigned to 2 subgroups. Composite resin material was bonded with the total-etch adhesive system in subgroups A1, B1, and C1 and with the self-etch adhesive system in subgroups A2, B2, and C2. The samples were thermo-cycled, and composite restorations shear bond strength was measured in MPa. Data were analyzed using two-way analysis of variance (ANOVA), and $P$ values less than 0.05 were considered statistically significant.

Results: The highest and the lowest shear bond strength values were observed in group A2 (Preparation by bur- Composite resin material bonded by Clearfil SE Bond) and group C2 (Preparation by laser with $400 \mathrm{~mJ}$ energy level - Composite resin material bonded by Clearfil SE Bond), respectively. The results showed no statistically significant differences between the study subgroups $(P>0.05)$.

Conclusion: It is concluded that in terms of shear bond strength to dentin, Single Bond and Clearfil SE Bond adhesive agents adequately perform in primary tooth dentin prepared by Er: YAG laser with energy levels of 300 and $400 \mathrm{~mJ}$ and frequency of $10 \mathrm{~Hz}$.

Keyword: Bonding agent; dentin; Er: YAG laser; Energy output; Primary teeth; Shear bond strength.
\end{abstract}

\section{Introduction}

Laser is an acronym for Light Amplification by Stimulated Emission of Radiation, and its application in medical and dental sciences has been described. ${ }^{1}$ One of the main uses of laser in dentistry is the removal of dental caries and preparation of restorative cavities. The use of laser with high power in preparation of cavities presents the advantages of less vibration and pain during procedure and reduced need for local anesthesia. ${ }^{2}$ Similarly, using laser in preparation of restorative cavities is accompanied with low risk of damage to adjacent teeth. ${ }^{3}$ It also makes the tooth structure more resistant to acid and decay. ${ }^{4}$

Amongst lasers used in dentistry, the erbium laser group with a cooling system has been proved by the Food and Drug Administration in 1997 to be the most effective and safest lasers for the preparation of dental surfaces. ${ }^{5} \mathrm{Er}-$ YAG laser with wavelength of $2940 \mathrm{~nm}$ is easily absorbed by water molecules and hydroxyl groups of dental tissue causing sudden heating and water vaporization. The resulting high stream pressure within the irradiated tissue leads to the occurrence of multiple micro explosions, tissue ablation and ejection of dental tissue particles. ${ }^{6}$

As laser acts with a different mechanism to prepare dental cavities, the morphology of laser prepared surfaces is different from that of those prepared by conventional method. Electron microscope scanning examination in laser-prepared permanent and primary tooth dentin reveals non-uniform scaly rough surfaces and opened

Please cite this article as follows: Paryab M, Sharifi S, Kharazifard MJ, Kumarci N. Cavity preparation by laser in primary teeth: effect of 2 levels of energy output on the shear bond strength of composite restoration to dentin. J Lasers Med Sci. 2019;10(3):235-240. doi:10.15171/ jlms.2018.38. 
tubules without formation of smear layer and any evidence of thermal damages. ${ }^{6-10}$ However, some others have reported inappropriate chemical changes in beneath the collagen network resulting in thin tags and irregular hybridization zone. ${ }^{11-13}$

The important matter is how the adhesive systems perform in the laser prepared tooth surfaces.

The adhesive systems have been designed for tooth dentin prepared by a conventional method so the differences in morphology and wettability of surfaces prepared by laser may affect the quality of the adhesive potential of bonding agents on these surfaces.

The adhesive potential of laser treated dentin in terms of bond strength and microleakage of the adhesive systems have been controversially discussed in the literature. Some studies found laser treatment to negatively influence the bond strength and leakage of adhesive dentin interface. ${ }^{14-21}$ Some other results have reported no difference in the bond strength or leakage of adhesive restorations between bur and laser prepared restorative cavities. ${ }^{22-25}$

At different laser parameters, different amount of tooth ablation and thermo-chemical changes occur on tooth surfaces, resulting in different performances from the same adhesives. Laser energy is one of the most important parameters affecting the characteristics of the prepared surface. The ideal energy for laser irradiation of different restorative material depends on the surface wettability and adaptability as well as the amount of adhesive demineralization; therefor, determining the appropriate laser energy level in the use of different adhesive systems would be crucial. Some limited studies by Roebuck et $\mathrm{al}_{,}{ }^{26,27}$ Monghini et $\mathrm{al}^{20}{ }^{20}$ Flury et $\mathrm{al}^{24}$ and Baghalian et $\mathrm{a}^{25}$ have investigated ideal laser energy for different restorative materials in permanent and primary dentitions.

It is necessary to evaluate the performance of different generations of adhesive systems at various settings of laser irradiation. This study aimed to assess the shear bond strength of a total-etch and self-etch adhesive system to primary tooth dentin irradiated with two different energy densities of Er-YAG laser in comparison with surfaces prepared with a bur.

\section{Methods \\ Prior to the main steps of the study, a pilot study was designed to determine the appropriate settings of the laser device. First, according to the previous studies, a range of 100-400 mJ for energy output and a range of $2-10 \mathrm{~Hz}$ for frequency were selected. Then, different levels of energies and frequencies were used to remove the buccal surfaces of some primary teeth. Two energies of $300 \mathrm{~mJ}$ and 400 $\mathrm{mJ}$ with a frequency of $10 \mathrm{~Hz}$ were recognized as the best laser parameters, with easier ablation of the dental tissue, appropriate speed for clinical practice and no signs of carbonization.}

A total of 60 human primary second molars were collected within a 6-month period and disinfected in $0.5 \%$ chloramine-T solution for 1 week. The specimens had no history of crown restoration or root canal treatment and were healthy for at least a third of the cervical root length. All teeth were examined with an explorer to rule out any enamel defects, cracks or caries on the buccal surface. The teeth were cleaned with water/pumice slurry to remove any residue and debris. According to the buccal surface preparation method, the samples were randomly divided into 3 main groups of equal $(n=20)$.

Group A: Preparation of Dentin Surface by Bur A guiding groove with a $2 \mathrm{~mm}$ depth was created on the buccal surface by high speed fissured bur (Teezkavan Co, Iran) and the buccal surface was removed with 120, 240, 400 and 600 grit silicone carbamide disc (Teezkavan Co, Iran) to expose a flat dentin.

Group B: Preparation of Dentin Surface by Laser With An Energy Level of $300 \mathrm{~mJ}$

A guiding groove with a $2 \mathrm{~mm}$ depth was created on the buccal surface by a short pulse Er-YAG dental laser (smart, DEKA, 2940D Plus, Italy) with a wavelength of $2940 \mathrm{~nm}$, pulse duration of $450 \mu \mathrm{s}$, focal spot size of $0.785 \mathrm{~mm}^{2}$, output energy of $300 \mathrm{~mJ}$ and frequency of $10 \mathrm{~Hz}$ along with air/water cooling system. The laser was delivered in a non-contact and defocused mode at a $0.8-1.2 \mathrm{~cm}$ distance from the surface with the beam perpendicular to the surface. The laser handpiece was moved in a right to left and anterior to posterior direction to prepare a flat dentin surface.

Group C: Preparation of Dentin Surface by Laser With the Energy Level of $400 \mathrm{~mJ}$

The guiding groove and flat dentin surface were created on the buccal surface by the same short pulse Er-YAG dental laser (smart, DEKA, 2940D Plus, Italy). The laser irradiation was set similarly to the laser irradiation used in group B. It was just different from the group B in terms of laser output energy level, which was $400 \mathrm{~mJ}$.

In each of the main groups, the teeth were randomly assigned to two subgroups according to the total etch adhesive system (A1, B1, and $\mathrm{C} 1$ ) and self etch adhesive system (A2, B2, and C2).

In the total etch adhesive system groups (A1, B1, and C1), the buccal surface of the teeth was etched with $35 \%$ etchant gel (Ultra etch, Ultradent product INC) for 5 seconds and then rinsed thoroughly for 5 seconds. Excess water was removed with oil-free compressed air in a blotted way to obtain teeth surfaces appearing wet. Two consecutive coats of Single Bond (Total etch adhesive system, 3M, EPSE, USA) were applied to etched dentin with gentle agitation using a fully saturated applicator. This was left undisturbed for 10 seconds, and the surface was then gently dried for 15 seconds to evaporate solvents and excess material. According to the 
manufacturer's instructions, the adhesive was light-cured for 10 seconds. Then, Z250 composite material (3M, ESPE, USA) condensed in a semi-transparent plastic mold with an internal diameter of $3 \mathrm{~mm}$ and height of $3 \mathrm{~mm}$ (as a matrix) was attached at the buccal surface of dentin forcefully with a plastic spatula. After wiping out of the extra composite around the matrix, it was cured with polymerizing light for 80 seconds (20 seconds per each side) with a visible light curing-unit (Coltolux 75, Colten, USA) with a $450 \mathrm{~mW} / \mathrm{mm}^{2}$ output energy. And this process was repeated after removal of the plastic mold (post-curing)

In the self etch adhesive system groups (A2, B2, $\mathrm{C} 2$ ), Clear fill SE Bond were placed according to the manufacturers' instructions. A drop of primer was applied on the dentin surface for 20 seconds using an applicator and then air-dried using a gentle air stream. Then a layer of bonding agent was applied on the surface using an applicator and cured for 10 seconds. Bonding of composite restoration material was performed similarly to the total etch adhesive groups.

According to the ISO/TR 11405 standardization, ${ }^{28}$ the samples were stored for at least 24 hours before testing in distilled water at $37^{\circ} \mathrm{C}$, and thermo cycled for 500 cycles between $5-55^{\circ} \mathrm{C}$, with a 50 seconds dwell time. All thermocycled samples were stored in distilled water for 24 hours at $37^{\circ} \mathrm{C}$. Following the thermo-cycling procedure, all samples were placed in the center of cold-cured acrylic resin blocks to assess the shear bond strength.

The acrylic blocks were fitted to a metallic ring in a universal testing machine (Zwick, Germany). The test knife edge blade was placed on the dentin-material interface along the long axis of each sample. Subsequently, a progressively increasing load with a cross-head speed of $0.5 \mathrm{~mm} / \mathrm{min}$ was used until dislodgement occurred. The load (force) required to dislodge the restoration was measured in Newton. To calculate the shear bond strength (SBS) in MPa, the measured load was divided by the cross-section of the bonding area $\left(\mathrm{mm}^{2}\right)$.

\section{Statistical Analysis}

The distribution of data was assessed using KolmogorovSmirnov method. Two-way analysis of variance (ANOVA) analysis was performed to analyze the mean of SBS in 6 experimental subgroups. $P$ values less than 0.05 were considered statistically significant.

\section{Mode of Fractures}

Blinded to the treatment conditions, 2 calibrated observers examined the fractured surfaces under a light microscope with 10X magnification and recorded the fracture modes, as following:

Type 1: Cohesive failure in composite material

Type 2: Adhesive failure at the composite and dentin interface

Type 3: Mixed adhesive and composite cohesive failures

\section{Results}

Shear Bond Strength

Sixty samples were assessed for shear bond strength (SBS). Minimum, maximum, the mean and standard deviation of SBS in each subgroup are presented in Table 1. Maximum bond strength values belonged to the samples prepared by bur followed by the samples prepared by laser with the energy level of $300 \mathrm{~mJ}$ and the samples prepared by laser with the energy level of $400 \mathrm{~mJ}$. The highest shear bond strength value was observed in group A2 and the lowest in group $\mathrm{C} 2$.

The means of SBS of 6 subgroups were analyzed using Two-Way ANOVA statistical analysis method and the results showed no statistically significant differences between the study subgroups $(P=0.397)$ (Figure 1$)$.

The fracture mode of samples in each subgroup is shown in Table 2. The mixed fracture mode was predominantly observed in study subgroups. Subgroup $B_{1}$ showed no adhesive fracture.

Table 1. Minimum, maximum, the Mean and Standard Deviation of SBS of Composite Resin to Primary Teeth Dentin in Study Subgroups

\begin{tabular}{lcccc}
\hline Groups & Minimum & Maximum & Mean & Standard Deviation \\
\hline $\mathrm{A}_{1}$ & 3.44 & 10.88 & 6.94 & 2.12 \\
$\mathrm{~A}_{2}$ & 5.72 & 13 & 9 & 2.47 \\
$\mathrm{~B}_{1}$ & 3.27 & 11.52 & 6.28 & 2.58 \\
$\mathrm{~B}_{2}$ & 2.36 & 13.47 & 6.42 & 3.9 \\
$\mathrm{C}_{1}$ & 3.26 & 11.05 & 6 & 3.16 \\
$\mathrm{C}_{2}$ & 2.47 & 12.47 & 5.62 & 2.99 \\
\hline
\end{tabular}

Subgroup $A_{1}$ : Bur preparation- Etching- Single Bond - Composite Bonding.

Subgroup $\mathrm{A}_{2}$ : Bur preparation- Clearfil SE Primer- Clearfil SE Bond Composite Bonding.

Subgroup $\mathrm{B}_{1}$ : laser preparation $(300 \mathrm{~mJ})$ - Etching- Single Bond Composite Bonding

Subgroup $B_{2}$ : laser preparation (300 mJ) - Clearfil SE Primer- Clearfil SE Bond - Composite Bonding.

Subgroup $\mathrm{C}_{1}$ : laser preparation $(400 \mathrm{~mJ})$ - Etching- Single Bond Composite Bonding.

Subgroup $\mathrm{C}_{2}$ : laser preparation $(400 \mathrm{~mJ})$ - Clearfil SE Primer- Clearfil SE Bond - Composite Bonding.

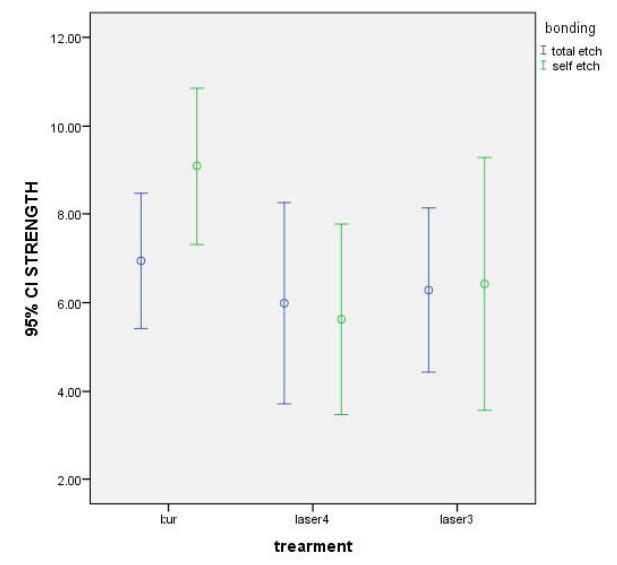

Figure 1. Error Bar of Mean and $95 \% \mathrm{Cl}$ of Composite Bond Strength to Primary Tooth Dentin in Using of Fifth and Sixth Generation Bonding Agents. 
Table 2. The Fracture Modes of Composite Resin Material in Study Subgroups

\begin{tabular}{lccc}
\hline Groups & Adhesive & Cohesive in Composite & Mixed \\
\hline $\mathrm{A}_{1}$ & 4 & - & 6 \\
$\mathrm{~A}_{2}$ & 5 & - & 5 \\
$\mathrm{~B}_{1}$ & - & 1 & 9 \\
$\mathrm{~B}_{2}$ & 3 & 3 & 4 \\
$\mathrm{C}_{1}$ & 5 & - & 5 \\
$\mathrm{C}_{2}$ & 2 & 1 & 7 \\
\hline
\end{tabular}

Subgroup $A_{1}$ : Bur preparation- Etching- Single Bond - Composite Bonding.

Subgroup $A_{2}$ : Bur preparation- Clearfil SE Primer- Clearfil SE Bond Composite Bonding.

Subgroup $B_{1}$ : laser preparation $(300 \mathrm{~mJ})$ - Etching- Single Bond Composite Bonding.

Subgroup $\mathrm{B}_{2}$ : laser preparation $(300 \mathrm{~mJ}$ ) - Clearfil SE Primer- Clearfil SE Bond - Composite Bonding.

Subgroup $C_{1}$ : laser preparation $(400 \mathrm{~mJ})$ - Etching- Single Bond Composite Bonding.

Subgroup $\mathrm{C}_{2}$ : laser preparation $(400 \mathrm{~mJ})$ - Clearfil SE Primer- Clearfil SE Bond - Composite Bonding.

\section{Discussion}

New technologies have been developed to find easier methods and achieve better treatment results. However, it is necessary to evaluate different aspects of new ones. The cavity preparation with the Er:YAG laser could be an alternative safe method for fearful children in pediatric dentistry. Therefore, it has been attempted to evaluate the performance of different adhesive systems which have different component, acidity and mechanism of interaction and establish the most appropriate laser parameters for the performance of these adhesive systems. The purpose of this study was to evaluate the shear bond strength of fifth and sixth generation adhesive systems to primary tooth dentin prepared with two different energies of laser.

In studies performed in this field, Roebuck et $\mathrm{al}^{26,27}$ found that in laser prepared permanent teeth, using laser irradiation with $350 \mathrm{~mJ}$ energy level prior to the application of composite restorative materials bonded with total-etch adhesive system and energy levels of 100-200-300/100 mJ prior to the application of compomer restorative materials bonded with self-etch adhesive system resulted in higher bond strength to dentin. Monghini et $\mathrm{al}^{20}$ reported that in laser prepared primary teeth, laser irradiation with energy level up to $100 \mathrm{~mJ}$ was appropriate in the bonding of composite restorative materials and total-etch adhesive system. In the study by Flury et al, ${ }^{24}$ using various settings of laser irradiation, favorable results in the bonding of composite restorative materials were observed. Baghalian et $\mathrm{al}^{25}$ found that using laser with an energy level of 200 $\mathrm{mJ}$, the composite material bonded with clearfil SE Bond had less marginal micro leakage in comparison with the compomer materials.

The parameters of Er-YAG laser used in this study were determined based on the previous studies of morphology and performance of adhesive systems in laser prepared surface. The energy levels of laser up to $300 \mathrm{~mJ}$ have been reported as safe energy outputs in primary teeth. ${ }^{29,30}$ The issue that the laser with an energy output of $400 \mathrm{~mJ}$ leads into melting, cracks or some areas of imperfection in dentin surfaces is a controversial issue. In a study by Zhang et $\mathrm{al}^{29}$ some areas of melting were reported, but in some studies, no signs of cracks or carbonization have been observed. ${ }^{24}$

Controversy also exists about the effect of the laser frequency of $10 \mathrm{~Hz}$. In the study by Flury et al, ${ }^{24}$ no cracks or carbonization was observed up to frequencies of $20 \mathrm{~Hz}$. In the study by Castilho et al, ${ }^{31}$ the results showed that irradiation of laser with the frequency of $14 \mathrm{~Hz}$ caused increased temperature in the safety zone. Frequency is the most important parameter in increasing temperature, rough surface, crack and fusion. ${ }^{32}$ In the pilot study, the frequency of $10 \mathrm{~Hz}$ was considered an ideal frequency in terms of clinical speed, so higher values of frequencies were not applied in this study to prevent the possible effect of frequency in increasing temperature of surrounding tissue.

Two frequently used bonding agent, single bond (totaletch adhesive system) and Clearfil SE Bond (self- etch adhesive system) were used in this study. Most studies have shown higher bond strength and lower marginal leakage of these bonding agents in primary teeth. ${ }^{33-35}$

The results of present study showed no statistically significant differences between the mean of the shear bond strength of the samples prepared by laser and bur. These results are in contrast to the results of studies by Torres et al, ${ }^{19}$ Bahrololoomi et $\mathrm{al}^{18}$ and Monghini et $\mathrm{al}^{20}$ who observed lower bond strength of composite to laser prepared primary tooth dentin. They disclosed that composite resin bonded with Single Bond adhesive agent had lower bond strength to laser prepared primary teeth dentin than in the bur prepared samples. They discussed that lower bond strengths to the laser prepared teeth could be due to the pulsing nature of laser creating a surface with an irregular pattern of roughness, subsurface microcracks, and fusion or micro-rupture of collagen fibrils resulting in the lack of appropriate resin penetration in these surfaces. ${ }^{17}$ And since laser irradiation increases the surface calcium-phosphorous ratio, resulting in a more resistant tooth surface to acid, so acid cannot eliminate the damaged subsurface. Laser parameters including energy density, frequency, pulse duration, distance from the target surface and the use of cooling system could affect the quality of these changes ${ }^{29,31,32,36}$; so, the difference between their results and ours may be attributed to different laser parameters used in these studies. Laser energy and frequency used in the studies by Bahrololoomi et al $(300 \mathrm{~mJ} / 2 \mathrm{~Hz}){ }^{18}$ Torres et $\mathrm{al}^{19}(200 \mathrm{~mJ} / 10 \mathrm{~Hz})$ and Monghini et $\mathrm{al}^{20}(100 \mathrm{~mJ} / 2 \mathrm{~Hz})$ were lower than in our studies $(300 \mathrm{~mJ} / 10 \mathrm{~Hz}, 400 \mathrm{~mJ} / 10 \mathrm{~Hz})$. Although no published data support this assumption, it seems that higher energy level and frequency of laser, of course in a safe range, increase the speed of ablation which may result 
in a lower chemical change of dentin surfaces. So, the performance of acid etchant solution on these surfaces would be more efficient. On the other hand, Single Bond adhesive agent containing alcohol and water as solvents in its formulation need a slightly moist substrate for optimal bonding; so, it can adapt and penetrate suitably to dentin surface prepared by laser.

The results of this study are consistent with the results obtained in the study by Flury et al. ${ }^{24}$ In both of these studies, higher levels of energy and frequency were used, and the results showed favorable bond strength of Clearfil SE bond up to the group prepared with conventional rotating instrument. Baghalian et $\mathrm{al}^{25}$ also disclosed the same favorable marginal leakage for the composite resin bound with Clearfil SE bond to the level of bur prepared cavity in a primary tooth. Clearfil Se Bond is a 2-step smear layer modifying bonding system (with the $\mathrm{pH}=2$ ) and is categorized as a mild self-etch system. In this system, depth of dentin demineralization and resin monomer penetration are equal and occur simultaneously. At the same time, Clearfil SE Bond has an important feature, which is, it contains 10-MDP (methacryloxy decyl dihydrogen phosphate) hydrophilic acidic monomer. It has a molecular structure capable of chemically reacting with hydroxy apatite remnants following acid etching. The produced chemical salt has hydrophilic stability. Several studies have attributed the high bond strength of Clearfil SE Bond to the presence of this monomer in its composition. ${ }^{37}$ Presence of MDP in this self-etch system in the present study may be responsible for their comparable bond strength to that of total etch systems.

Bonding to permanent teeth has been studied extensively. The results of this study about the performance of Single Bond and Clearfil SE Bond were in accord with those by Celik et $\mathrm{al}^{22}$ and da Silva et $\mathrm{al}^{23}$ and in contrast to the studies by Ramos et al, ${ }^{15}$ De Munck et al, ${ }^{17}$ and Koliniotou-Koumpia et al. ${ }^{14}$ The results of the present study cannot be reliably compared to the outcomes of the conducted research on the permanent teeth. Many studies have suggested that the permanent tooth dentin has some morphological and structural differences in comparison with primary tooth dentin..$^{38,39}$ Different mineral and water content of primary tooth dentin result in a different ablation threshold of laser irradiation and thermal changes of the tooth surface. Different number and diameter of dentin tubules of primary tooth dentin lead to the different reactivity of primary tooth dentin to the acidic solutions.

It should be kept in mind that other different practical condition of tooth structure such as carious tissue, different tooth anatomy and chemical component and presence of sclerotic dentin can affect water amount, ablation threshold and removal of the dental structure. So, it is definitely a hindrance to extend the results of an in vitro study to practice conditions. These results are to be confirmed in the future with studies encompassing more samples and clinical situations.

Further evaluation of changes occurring in the primary tooth dentin prepared by laser in the setting of this study in terms of the amount of ablation (interferometry), melting, surface cracking or carbonization, TEM ultra structure analysis and changes in chemical compositions of tooth structure, is recommended.

\section{Conclusion}

Based on the current study's findings, and within the limitations of an in vitro investigation, Er:YAG laser with two energy of 300 and $400 \mathrm{~mJ}$ and frequency of $10 \mathrm{~Hz}$ can be used in preparing restorative cavities of primary teeth with proper clinical speed. It may be concluded that in terms of shear bond strength, Single Bond and Clearfil SE Bond adhesive agents adequately perform in primary tooth dentin prepared by Er: YAG laser with the energy level of $300 \& 400 \mathrm{~mJ}$ and $10 \mathrm{~Hz}$.

\section{Conflict of Interests}

None.

\section{Ethical Considerations}

This in vitro study was approved by the Ethics Committee of Tehran University of Medical Sciences, Iran.

\section{Acknowledgments}

The authors would like to thank Dr. Hooman Ebrahimi for his sincere cooperation.

\section{References}

1. Sulewski JG. Historical survey of laser dentistry. Dent Clin North Am. 2000;44(4):717-752.

2. Olivi G, Genovese MD, Caprioglio C. Evidence-based dentistry on laser paediatric dentistry: review and outlook. Eur J Paediatr Dent. 2009;10(1):29-40.

3. Yildiz E, Sirinkaraarslan E, Yegin Z, Cebe MA, Tosun G. Effect of caries removal techniques on the bond strength of adhesives to caries-affected primary dentin in vitro. Eur J Paediatr Dent. 2013;14(3):209-214.

4. Chaiyavej S, Yamamoto H, Takeda A, Suda H. Response of feline intradental nerve fibers to tooth cutting by Er:YAG laser. Lasers Surg Med. 2000;27(4):341-349.

5. Pelagalli J, Gimbel CB, Hansen RT, Swett A, Winn DW, 2nd. Investigational study of the use of Er:YAG laser versus dental drill for caries removal and cavity preparation-phase I. J Clin Laser Med Surg. 1997;15(3):109-115. doi:10.1089/clm.1997.15.109

6. Keller U, Hibst R. Experimental studies of the application of the Er:YAG laser on dental hard substances: II. Light microscopic and SEM investigations. Lasers Surg Med. 1989;9(4):345-351.

7. Freitas PM, Navarro RS, Barros JA, de Paula Eduardo C. The use of Er:YAG laser for cavity preparation: an SEM evaluation. Microsc Res Tech. 2007;70(9):803-808. doi:10.1002/jemt.20470

8. Kornblit R, Bossu M, Mari D, Rocca JP, Polimeni A. Enamel and dentine of deciduous teeth Er:YAG laser prepared. A SEM study. Eur J Paediatr Dent. 2009;10(2):75-82. 
9. de Oliveira Ortolan AS, Torres CP, Gomes-Silva JM, et al. Effect of erbium-doped yttrium aluminium garnet laser parameters on ablation capacity and morphology of primary dentin. Photomed Laser Surg. 2009;27(6):885-890. doi:10.1089/pho.2008.2358

10. Al-Batayneh OB, Seow WK, Walsh LJ. Assessment of Er:YAG laser for cavity preparation in primary and permanent teeth: a scanning electron microscopy and thermographic study. Pediatr Dent. 2014;36(3):90-94.

11. Schein MT, Bocangel JS, Nogueira GE, Schein PA. SEM evaluation of the interaction pattern between dentin and resin after cavity preparation using ER:YAG laser. J Dent. 2003;31(2):127-135.

12. Barceleiro Mde O, de Mello JB, de Mello GS, Dias KR, de Miranda MS, Sampaio Filho HR. Hybrid layer thickness and morphology: the influence of cavity preparation with Er:YAG laser. Oper Dent. 2005;30(3):304-310.

13. Camerlingo C, Lepore M, Gaeta GM, et al. Er:YAG laser treatments on dentine surface: micro-Raman spectroscopy and SEM analysis. J Dent. 2004;32(5):399405. doi:10.1016/j.jdent.2004.01.011

14. Koliniotou-Koumpia E, Kouros P, Zafiriadis L, Koumpia E, Dionysopoulos P, Karagiannis V. Bonding of adhesives to Er:YAG laser-treated dentin. Eur J Dent. 2012;6(1):16-23.

15. Ramos RP, Chinelatti MA, Chimello DT, Borsatto MC, Pecora JD, Palma-Dibb RG. Bonding of self-etching and total-etch systems to Er:YAG laser-irradiated dentin. Tensile bond strength and scanning electron microscopy. Braz Dent J. 2004;15 Spec No:Si9-20.

16. Ramos RP, Chimello DT, Chinelatti MA, Nonaka T, Pecora JD, Palma Dibb RG. Effect of Er:YAG laser on bond strength to dentin of a self-etching primer and two singlebottle adhesive systems. Lasers Surg Med. 2002;31(3):164170. doi:10.1002/lsm.10106

17. De Munck J, Van Meerbeek B, Yudhira R, Lambrechts $P$, Vanherle G. Micro-tensile bond strength of two adhesives to Erbium:YAG-lased vs. bur-cut enamel and dentin. Eur J Oral Sci. 2002;110(4):322-329.

18. Bahrololoomi Z, Kabudan M, Gholami L. Effect of Er:YAG Laser on Shear Bond Strength of Composite to Enamel and Dentin of Primary Teeth. J Dent (Tehran). 2015;12(3):163170.

19. Torres CP, Gomes-Silva JM, Borsatto MC, Barroso JM, Pecora JD, Palma-Dibb RG. Shear bond strength of self-etching and total-etch adhesive systems to Er:YAG laser-irradiated primary dentin. J Dent Child (Chic). 2009;76(1):67-73.

20. Monghini EM, Wanderley RL, Pecora JD, Palma Dibb RG, Corona SA, Borsatto MC. Bond strength to dentin of primary teeth irradiated with varying Er:YAG laser energies and SEM examination of the surface morphology. Lasers Surg Med. 2004;34(3):254-259. doi:10.1002/lsm.20023

21. Bahrololoomi Z, Heydari E. Assessment of Tooth Preparation via Er:YAG Laser and Bur on Microleakage of Dentin Adhesives. J Dent (Tehran). 2014;11(2):172-178.

22. Celik EU, Ergucu Z, Turkun LS, Turkun M. Shear bond strength of different adhesives to Er:YAG laser-prepared dentin. J Adhes Dent. 2006;8(5):319-325.

23. da Silva MP, Barceleiro MO, Dias KR, Zanin F. Shear bond strength of two adhesive systems bonded to Er:YAG laserprepared dentin. Gen Dent. 2011;59(3):e96-100.

24. Flury S, Koch T, Peutzfeldt A, Lussi A. Micromorphology and adhesive performance of Er:YAG laser-treated dentin of primary teeth. Lasers Med Sci. 2012;27(3):529-535. doi:10.1007/s10103-011-0882-5

25. Baghalian A, Nakhjavani YB, Hooshmand T, Motahhary P, Bahramian H. Microleakage of Er:YAG laser and dental bur prepared cavities in primary teeth restored with different adhesive restorative materials. Lasers Med Sci. 2013;28(6):1453-1460. doi:10.1007/s10103-012-1222-0

26. Roebuck EM, Saunders WP, Whitters CJ. Influence of Erbium:YAG laser energies on the microleakage of Class V resin-based composite restorations. Am J Dent. 2000;13(5):280-284.

27. Roebuck EM, Whitters CJ, Saunders WP. The influence of three Erbium:YAG laser energies on the in vitro microleakage of Class $\mathrm{V}$ compomer resin restorations. Int $\mathrm{J}$ Paediatr Dent. 2001;11(1):49-56.

28. Siadat $\mathrm{H}$, Mirfazaelian A. Microleakage and its measurement methods. J Dent Med(TUMS). 2002;15(2):70-81.

29. Zhang S, Chen T, Ge LH. Scanning electron microscopy study of cavity preparation in deciduous teeth using the Er:YAG laser with different powers. Lasers Med Sci. 2012;27(1):141-144. doi:10.1007/s10103-010-0854-1

30. Guler C, Malkoc MA, Gorgen VA, Dilber E, Bulbul M. Effects of Er:YAG laser on mineral content of sound dentin in primary teeth. Scientific WorldJournal. 2014;2014:578342. doi:10.1155/2014/578342

31. Castilho MS, de Souza-Gabriel AE, Marchesan MA, Floriam LJ, Sousa-Neto MD, Correa Silva-Sousa YT. Temperature changes in the deciduous pulp chamber during cavity preparation with the Er:YAG laser. J Dent Child (Chic). 2007;74(1):21-25.

32. Brandao CB, Contente MM, De Lima FA, et al. Thermal alteration and morphological changes of sound and demineralized primary dentin after Er:YAG laser ablation. Microsc Res Tech. 2012;75(2):126-132. doi:10.1002/ jemt.21034

33. Marquezan M, da Silveira BL, Burnett LH, Jr., Rodrigues CR, Kramer PF. Microtensile bond strength of contemporary adhesives to primary enamel and dentin. J Clin Pediatr Dent. 2008;32(2):127-132.

34. Thanaratikul B, Santiwong B, Harnirattisai C. Self-etch or etch-and-rinse mode did not affect the microshear bond strength of a universal adhesive to primary dentin. Dent Mater J. 2016;35(2):174-179. doi:10.4012/dmj.2015-109

35. Agostini FG, Kaaden C, Powers JM. Bond strength of selfetching primers to enamel and dentin of primary teeth. Pediatr Dent. 2001;23(6):481-486.

36. Shirani F, Birang R, Malekipour MR, Hourmehr Z, Kazemi $S$. Shear bond strength of resin composite bonded with two adhesives: Influence of Er: YAG laser irradiation distance. Dent Res J (Isfahan). 2014;11(6):689-694.

37. Mortazavi V, Fathi M, Ataei E, Khodaeian N, Askari N. Shear bond strengths and morphological evaluation of filled and unfilled adhesive interfaces to enamel and dentine. Int J Dent. 2012;2012:858459. doi:10.1155/2012/858459

38. Sumikawa DA, Marshall GW, Gee L, Marshall SJ. Microstructure of primary tooth dentin. Pediatr Dent. 1999;21(7):439-444.

39. Nor JE, Feigal RJ, Dennison JB, Edwards CA. Dentin bonding: SEM comparison of the dentin surface in primary and permanent teeth. Pediatr Dent. 1997;19(4):246-252. 